\title{
Convection influence on ice formation process on the evaporator heat pump pipes
}

\author{
Vyacheslav Maksimov ${ }^{1, *}$, and Saloum Amer ${ }^{1}$ \\ ${ }^{1}$ National Research Tomsk Polytechnic University, 634050 Tomsk, Russia
}

\begin{abstract}
The purpose of this research is to identify the effect of convection on the ice growth process on the evaporator of heat pump, and how this growth can affect the heat exchange, and the evaporator performance. An experimental analyse is done on the heat pump station which depends on water as heat source. A 2D model is built in Comsol environment depending on Brinkman and heat transfer equations. The experimental and mathematical simulation results confirm that the ice formation has a negative effect on the evaporator heat exchange efficiency, and the convection has high effect on ice growth rate and this effect increases when the pipe is closer to the heat exchanger base. The effect of block size on the convection and ice growth rate must be studied in future.
\end{abstract}

\section{Introduction}

The ice formation on a surface is a special case of classical Stefan problem [1], which aims to describe the temperature gradient in medium undergoing phase change.

A lot of studies are available for freezing problem in pipe flow $[2,3]$, but there are no studies for the effect of convection on ice formation on a cylindrical pipe, the heat transfer analysis undergoing convection and phase change is needed for the applications which include the use of pipes with temperature under zero in water.

Freezing problem in pipe flow case was studied by Jong Suk Lee from Iowa state university of USA, and they concluded that the ice layer profile at the final steady state increases linearly along the test section. Stefan number, and thermal conductivity affect the freezing rate and freezing time, but do not change the steady state ice layer profile, and the pressure drop along horizontal pipe has significant effect on ice growth rate [1].

\section{Experimental technique}

An experimental study is done to analyze the ice formation process and heat exchange in the heat pump evaporator (fig. 1). The experimental method is explained in [4].

\footnotetext{
*Corresponding author: elf@tpu.ru
} 


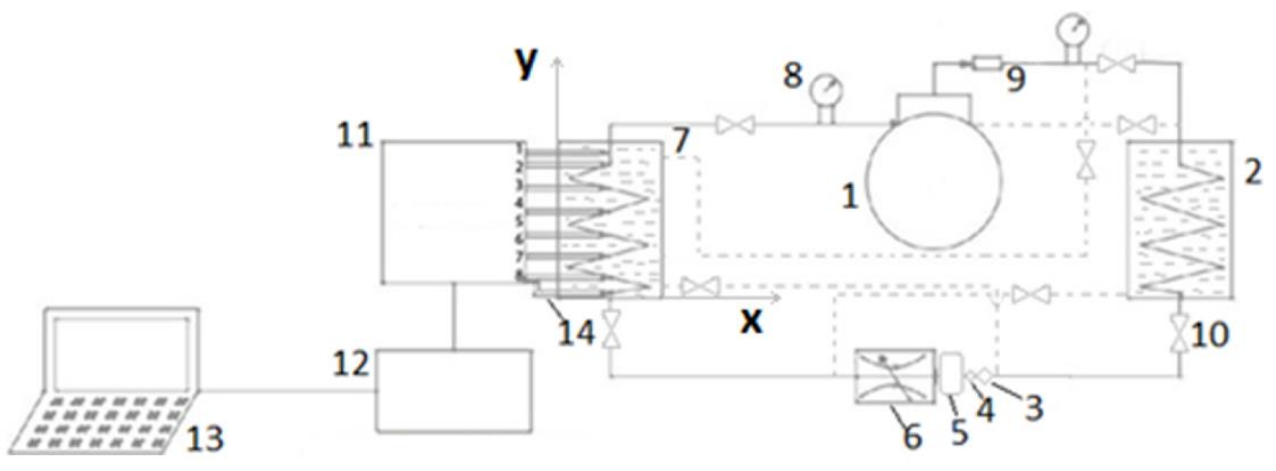

Fig. 1. Scheme of the experiment: 1 - compressor; 2 - the condenser; 3 - filter; 4 - sight window; 5 drier; 6 - capillary tube; 7 - Evaporator; 8 - manometer; 9 - flowmeter; 10 - valve; 11 - digital thermometer; 12 - converter; 13 - computer; 14 - thermocouple.

If the effect of convection is ignored, the next equations can be used to describe the ice formation process:

$$
\begin{gathered}
\delta=\frac{\frac{\Delta T_{W}}{\ln \frac{r_{W}}{r_{P}} \cdot 2 \cdot \pi \cdot K_{W}}}{\left(r_{W} \cdot C_{P, W} \cdot \frac{d T_{W}}{d t}+\frac{I_{i} \cdot \rho_{i}}{d y}\right) \cdot 2 \cdot \pi \cdot r_{P}} \\
I_{i} \cdot \rho_{i} \cdot 2 \cdot \pi \cdot r_{i} \cdot \frac{d r_{i}}{d t}=\frac{\Delta T_{i}}{\ln \frac{r_{i}}{r_{p}} \cdot 2 \cdot \pi \cdot K_{i}-\frac{\Delta T_{W}}{\ln \frac{r_{W}}{r_{i}}} \cdot 2 \cdot \pi \cdot K_{W}}
\end{gathered}
$$

where $\delta$ - initial ice thickness; $T_{w}$ - water temperature; $\mathrm{T}_{\mathrm{i}}-$ ice temperature; $\mathrm{r}_{\mathrm{w}}$-the distance between the pipe center and the temperature sensor; $\mathrm{K}_{\mathrm{w}}-$ water thermal conductivity; $\mathrm{K}_{\mathrm{i}}$ - ice thermal conductivity; $\mathrm{r}_{\mathrm{p}}$ - pipe radius; $\mathrm{r}_{\mathrm{i}}$ - ice radius; $\mathrm{C}_{\mathrm{p}, \mathrm{w}}-$ water heat capacity; $\rho_{\mathrm{i}}-$ ice density; $\rho_{\mathrm{w}}$ - water density; $\mathrm{I}_{\mathrm{i}}$-latent heat of freezing.

Ice growth Stops when the following condition is available:

$$
\frac{r_{\text {Ice }(\text { Maximum })}}{r_{\text {pipe }}}=e^{\frac{2}{S u \cdot N u}}
$$

where $\mathrm{Nu}-$ Nusselt number.

$$
S u=\frac{k_{W} \cdot\left(T_{0}-T_{W}\right)}{k_{I} \cdot\left(T_{I}-T_{0}\right)}
$$

where $\mathrm{Su}$ - number of superheating.

The convection effect on ice growth rate can be seen in Fig.2, It is noticed that this effect is higher, when the pipe height is less (when the pipe is closer to the base of heat exchanger) (c, d), and the difference between theoretical and experimental curve is bigger when the convection effect is higher which can be concluded by comparing (a), (b) with (c), (d) in fig. 2 . 


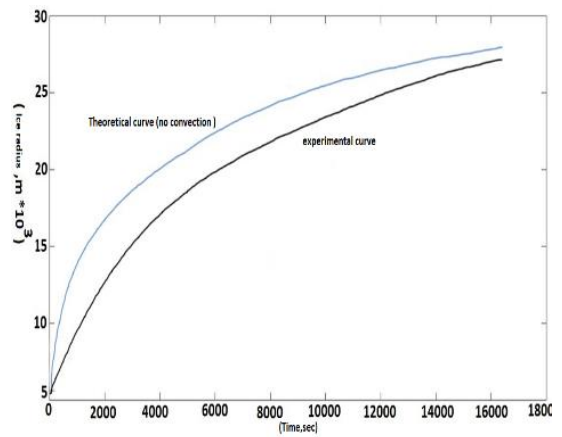

(a)

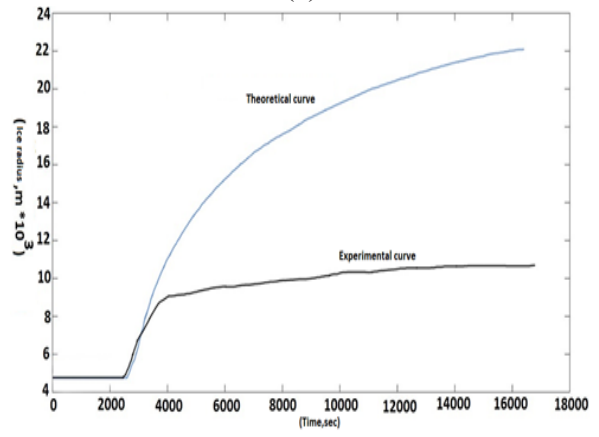

(c)

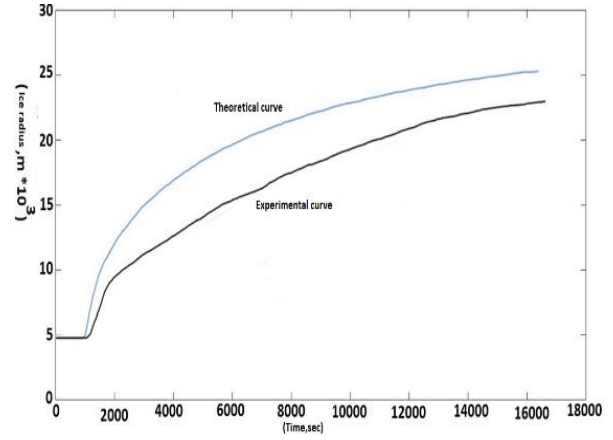

(b)

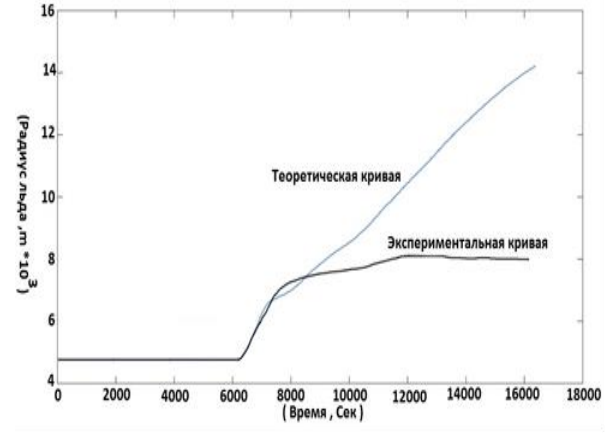

(d)

Fig. 2. Theoretical (without convection) and experimental ice radius versus time at different heights $(22,17.5,15,12.5) \mathrm{cm}$ with $(\mathrm{a}, \mathrm{b}, \mathrm{c}, \mathrm{d})$ consequently.

\section{Simulation study}

2D model is built the block dimensions are $(10 \times 10) \mathrm{cm}$ and the pipe in the center on the block with diameter $9.54 \mathrm{~mm}$. The following assumptions are taken into consideration: the ice layer is static and nondeformable, the average ice permeability $10^{-12} \mathrm{~m}^{2}$, transition interval between water and ice is $1 \mathrm{~K}$. Brinkman, phase change, and heat transfer in fluid equations are used for the calculations in the model [5]. The initial water temperature is 280 $\mathrm{K}$, the boundary temperature for the pipe wall is $263 \mathrm{~K}$. The walls of water container are full isolated. The model was built by coupling the heat transfer with flow equations. As the water turns into ice the permeability in the freezing zone is decreased to a very small value. The temperature gradient with height in different moments can be seen in Fig.3.

And the modeling results agree with the experimental results which were published in [4], which confirm the fact that when the temperature is more than $277.15 \mathrm{~K}$ the temperature increase with height, but when temperature is less than 277.15 , it decreases with height. The velocity diagrams are shown in fig.4. The water flow moves downwards in the first $420 \mathrm{sec}$ and after that the flow direction changes to upward because of the changes in water density with temperature.

In Fig.5. (a) The heat flux around the pipe changes with time, line number 3 represent the case where the phase change is ignored. Fig.5. (b) represents the ice growth with time, line number 1 represent the case of ice growth if the effect of convection is ignored. It is noticed that when the ice thickness increases, the heat exchange rate decreases, that means that the ice growth has a bad effect on heat exchange, in spite of the fact that the coefficient 
of ice thermal conductivity $(2.16 \mathrm{~W} / \mathrm{m} \cdot \mathrm{K})$ is higher than the liquid water thermal conductivity $(0.54 \mathrm{~W} / \mathrm{m} \cdot \mathrm{K})$.
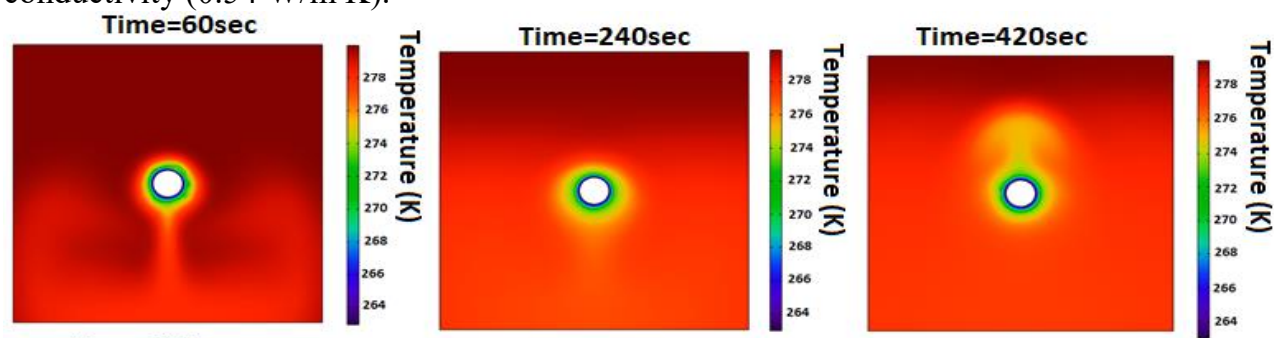

Time $=600 \mathrm{sec}$
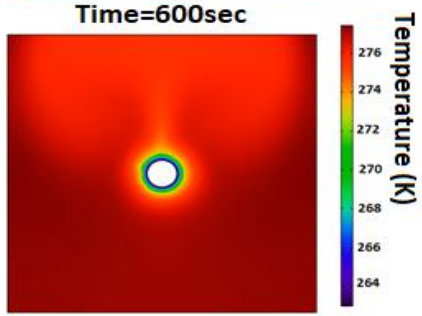

Time $=780$ sec

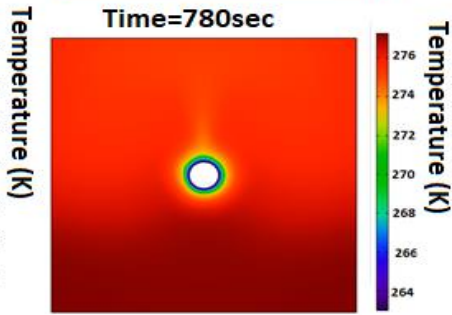

Time $=1000 \mathrm{sec}$

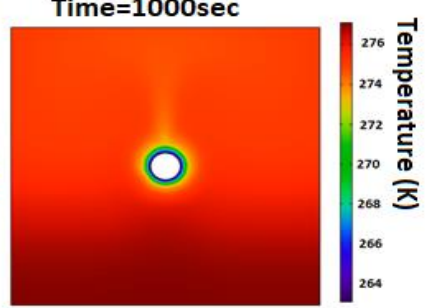

Fig. 3. Temperature diagrams.

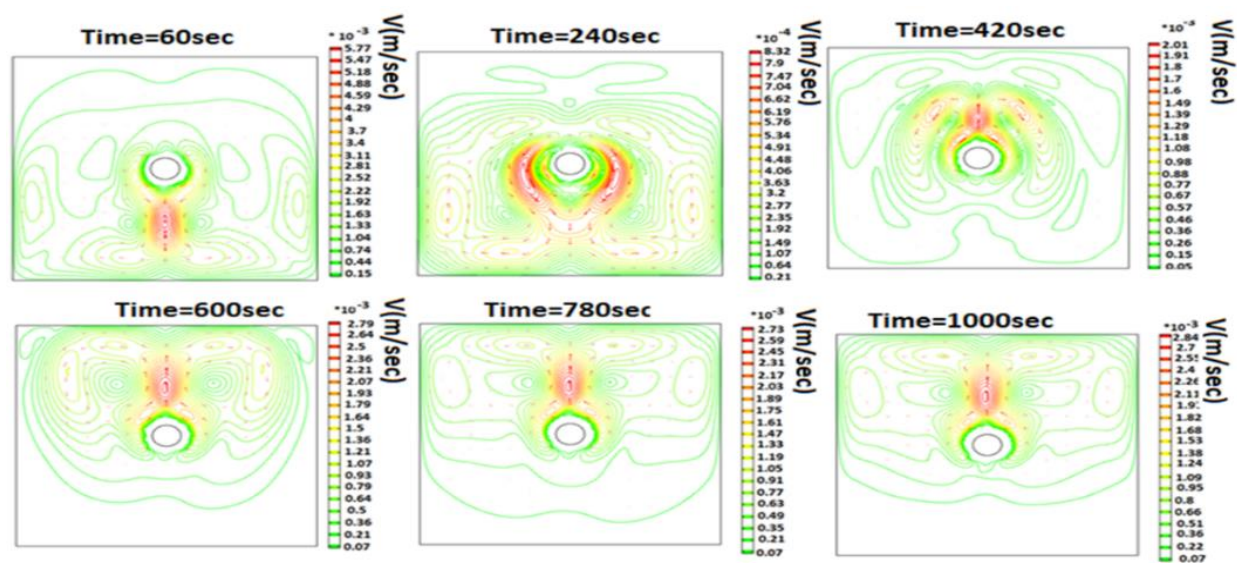

Fig. 4. Velocity diagrams.

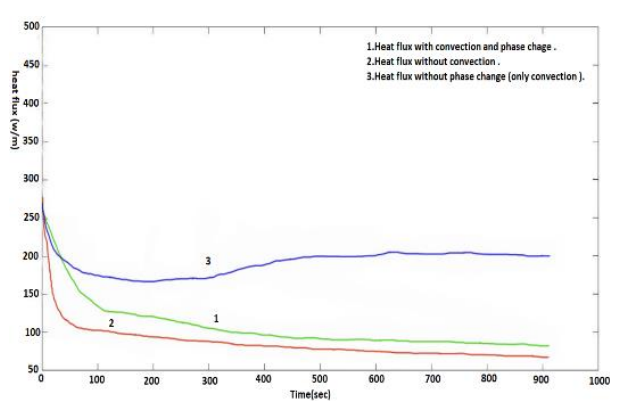

(a)

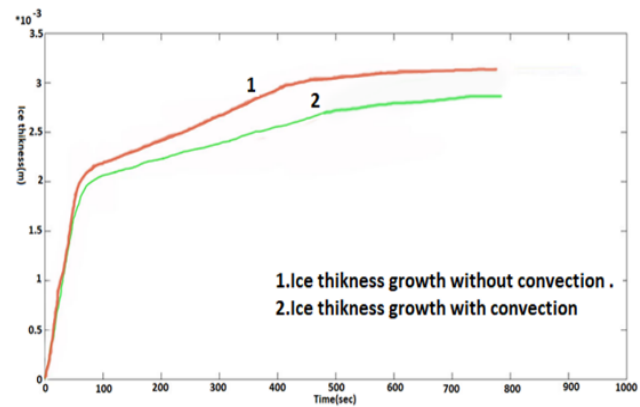

(b)

Fig. 5. Heat flux with time (a), Ice thickness change with time (b). 


\section{Conclusion}

Temperature values in the main nodes of the heat pump plant are registered, the temperature sensors are placed on the surface of the heat evaporator pipes, and at different heights in the evaporator container, the thickness of the ice on the surface of the evaporator pipe is measured. With the use of energy equation, the ice thickness change with time is also calculated.

It is concluded that the difference between the ice thickness values which are obtained analytically and experimentally can exceed 50\%, depending on the height of the pipe in the evaporator container. Mathematical model is built for heat exchange case including convection and phase change, A comparing is done between heat flux values in the case of convection and without it. It can be concluded that, convection currents are formed around the pipe and these currents have a significant effect on ice formation, It is found that in case of neglecting convection in the model the ice thickness is less by $16 \%$.

The article results can be used to assess the heat pump performance in the case of ice formation on the evaporator pipes in water source heat pump systems «autumn, winter, and spring», which will help to improve the efficiency calculating methods for water -heat pump systems.

The work was supported by the Russian President's grant (Scientific School project 7538.2016.8).

\section{References}

1. J.S. Lee, Freezing problem in pipe flows (Iowa State University, Ames, 1993)

2. T.A. Kwaleweski, A. Cublski, Int. Conf. on Heat Transfer with Change of Phase, 61, 2 (1996)

3. V.I. Maksimov, T.A. Nagornova, V.S. Chernyshev, MATEC Web of Conferences, 23, 01051 (2015), DOI:10.1051/matecconf/20152301051

4. V.I. Maksimov, A. Saloum, MATEC Web of Conferences, 110, 01074 (2017), DOI:10.1051/matecconf/201711001074

5. R. Hu, Q. Liu. Excerpt from the Proceedings of the COMSOL Conference in Munich, (2016) 